\title{
Biases in Charitable Giving to International Humanitarian Aid:
}

\section{The Role of Psychic Distance}

"I am hard pressed to think of a greater academic agenda than to focus one’s scholarship on policies and practices to help our fellow global citizens recovering from natural or human induced disasters.”

Clifford J. Shultz II, Editor, Journal of Macromarketing, Vol. 25, No. 1, June 2005, pg. 3-4

\section{Introduction}

In 2010, there was a generous outpouring of charitable support by Canadians for victims of the Haitian Earthquake. These donations were sent to a group of beneficiaries that the donors would probably never meet, in a country they would probably never visit. Why were Canadians so willing to help these specific distant strangers? Individual donations by Canadians to the 2010 Haitian earthquake relief campaigns totaled more than $\$ 220$ million, and yet Canadian donations to the 2010 Pakistan flood relief campaigns, for another group of beneficiaries Canadians would likely never meet or visit, were only $\$ 46.8$ million, or $21 \%$ the total amount given to the Haitians (Galloway 2012). To look at it another way, the donations to Haitians were approximately $\$ 63$ 'per person affected' while donations to the Pakistanis were only $\$ 2.30$ 'per person affected'. Why did the Haitian victims receive on a per person basis twenty-seven times the support of the Pakistani victims? This paper explores one potential reason - the role that psychic distance may play in biasing humanitarian aid donations by individuals. 
Such biases are particularly critical given the worrisome trends in Canadian government support for international aid and in Canadian individual giving to international charities and development. Although Canada is a country with strong ties around the world and a proportionally large foreign-born population, Canadian federal government spending on foreign aid has dropped significantly since 2010. In 2011, Canada’s foreign aid spending was $\$ 5.7$ billion, falling to $\$ 5.4$ billion in 2013, and $\$ 4.9$ billion in 2014 (Canadian International Development Platform 2015). According to the OECD (2014), the drop in 2014 of $11.4 \%$ in official development assistance was the largest annual drop in the world. This contribution represents only $0.24 \%$ of Gross National Income, down from $0.27 \%$ in the previous year (Canadian International Development Platform 2015), and well short of United Nations targets of $0.7 \%$ of GNI (United Nations 2015). These trends are not limited to Canada, as the OECD (2017) reports that 23 of 29 OECD Development Assistance Committee countries fell below this target, leaving only 6 countries (Germany, Denmark, Luxembourg, Norway, Sweden, the United Kingdom) meeting the UN targets. In Canada, analysts posit that these cuts to international aid from 2010 to 2014 are a direct result of the government's attempts to balance the books ahead of a 2015 federal election (Greenhill 2017).

In 2016, there were approximately 164 million people in 47 countries in need of IHA (Development Initiatives 2017). Funding from all sources, public and private, directed to the 43 United Nations coordinated appeals still left a 40\% shortfall with a 95\% gap in funding levels between the best and worst funded appeals (Development Initiatives 2017). At a time when government support for international aid is slowing amidst persistent shortages, organizations devoted to helping are looking ever more to the individual donor for financial contributions as giving by individuals represents the largest and fastest growing segment of non-government donors (IUPUI 2017). These organizations' operations and marketing 
budgets are under intense scrutiny and stretched with resources at near capacity, often working in multiple countries around the world (Reimann 2017). Research that could help marketers and fundraisers in international humanitarian aid (IHA) decide how best to use their limited budgets has been, at best, scarce (Ülkü, Bell, and Wilson 2015).

This paper represents our initial steps into investigating the role of IHA in marketing systems. We take up Shultz's (2005) call and agree that macromarketers are ideally situated to tackle the wicked problems associated with humanitarian relief because of the enormity of the repercussions for mankind as well as the complexity and diversity of the systems in which the actors must operate. The depiction of the "other" in marketing has significant ideological consequences and addresses one of the central tenants of macromarketing; how marketing affects society.

In this submission, we begin to examine one aspect of the system, charitable fundraising by international humanitarian aid agencies. We seek better understanding of the relationship between private donors, international NGOs, the distant other they wish to help, and the respective societies in which they operate. We begin with a description of the marketing system associated with IHA. This then leads us to the introduction of the concept of psychic distance to the macromarketing literature and an exploration of the role of psychic distance in fundraising for international humanitarian aid.

\section{The Marketing System of International Humanitarian Aid}

A marketing system represents the network of stakeholders connected to the delivery of value to customers through the offer of goods or services in response to customer demand (Layton 2007). The IHA system (see Figure 1) could be considered such a system, with some important differences, as it includes a variety of individuals and organizations that require a "process for managing the flow of goods, information and finances from donors to affected 
persons” (Ernst 2003, p. 5). The macromarketing literature has examined similar marketing systems such as those involved in natural disaster recovery (Baker 2009; Baker et al. 2015), post-war rebuilding and transition economies (Barrios et al. 2016; Sredl, Shultz, and Brečić 2017; Shultz 1997; Shultz 2015; Shultz and Pecotich 1997), as well as with vulnerable and subsistence consumers (Baker 2009; Saatcioglu and Corus 2014; Viswanathan, et al. 2014; Viswanathan, Rosa, and Ruth 2010).

The IHA system, as depicted in Figure 1, includes those in the outer circle who represent stakeholders who facilitate or enable the supply chain and delivery of humanitarian aid (adapted from Kovács and Spens 2007) while the inner circle represents the physical process of delivering said aid (adapted from Oloruntoba and Gray 2006). Each IHA marketing system is unique to reflect the specific circumstances of the location, the governments, and organizations involved as well as cultural, economic, and historic factors (Layton 2015). As such, the position of some stakeholders may move between inner and outer circle depending on circumstance. This movement is noted by the dotted line of the inner circle. Aid programs in developing countries are singled out by Layton (2015) as a prime example of the changes that must occur in specific marketing systems depending on local context while maintaining the broader focal marketing system.

Figure 1: The International Humanitarian Aid System 


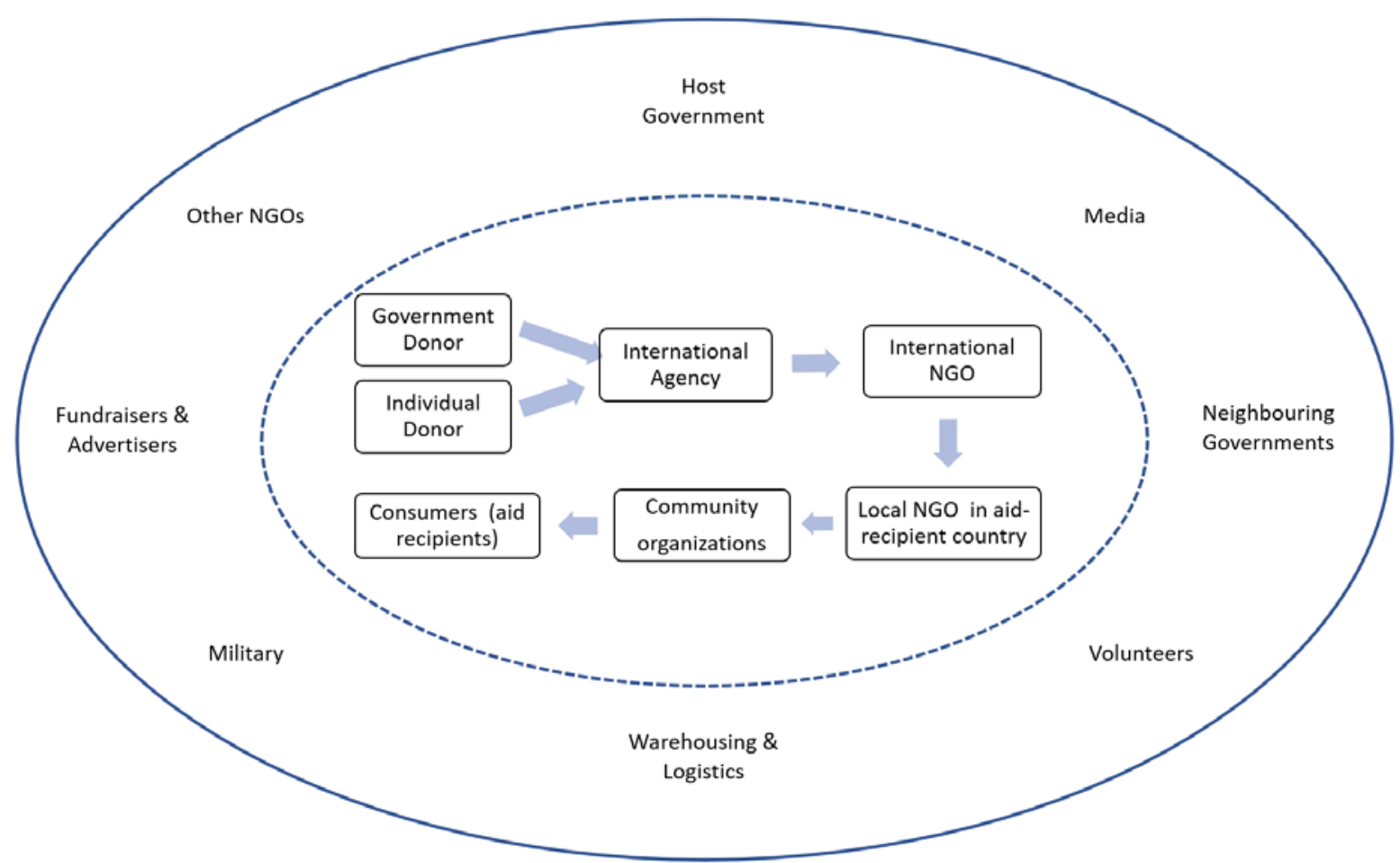

According to the typology outlined by Layton (2015), the IHA marketing system could be classified as a composite system that combines horizontal, vertical, and facilitating modes. The horizontal mode is represented by multiple market locations for both the collection of aid funds from donors as well as the distribution of services in locations such as refugee shelters, food distribution centers, and emergency centers across various countries. The vertical mode highlights the movement of goods and services through the supply chain and distribution channels, turning online donations into relevant goods (water, food, shelters) in remote and devastated regions. There are also numerous facilitating systems present to enable the transmission of data, financing, and logistic support.

Furthermore, the IHA system contains processes that exist and interact on multiple levels of social systems (Layton 2015). The micro-level of individual transactions exists at both ends of the IHA marketing system. At one end, private donors make individual donations of cash or goods to help the distant other. At the other end, the distant other in need 
receives the necessary aid products or services. The meso-level market structures including local organizations facilitate the collection and distribution of aid in partnership with various stakeholders such as military, volunteers, and logistics support. At the macro-level, the various governments and international organizations create the necessary dynamics for the system to operate. The IHA system is also characterized by three phases of development including preparation, immediate response, and reconstruction (Christopher and Tatham 2011).

When discussing IHA systems, there are, however, several important distinctions from traditional marketing or business systems. The primary difference is that the customer (or the aid recipient) has no choice in who they receive the aid from, would rather not be a customer, and even less desire to be a repeat or loyal customer (Kovács and Spens 2007). Customer demand in the market is not determined by customers themselves but rather activated by exogenous events such as droughts, earthquakes, and wars, with aid agencies monitoring and assessing these needs (Long and Wood 1995). These aid agencies are the primary actors through which aid is funneled. The largest agencies are global actors, but there are also many small regional and country-specific aid agencies (Thomas and Kopczak 2005).

Donors are important actors as they provide the bulk of funding for major relief activities. The list of donors includes foreign governments, foundations, individual donors and the private sector (Kovacs and Spens 2007). Other actors include the military (Özdamar, Ekinci, and Küçükyazici 2004), host governments and neighboring country governments, other non-governmental organizations, logistics service providers (Kaatrud, Samii, and van Wassenhove 2003), volunteers (Beigbeder 1991) and the media (Höijer 2004).

The integration of IHA and marketing systems theory has several implications and raises some important theoretical and conceptual questions. While both take a structural view, 
it could be argued that the primary focus of the IHA approach is the aid recipient and thus begins at the micro-level, the marketing systems approach begins with a more macro-level perspective. Additionally, marketing systems are about the network and relationships while the theory underlying IHA is focused on the flow of good and capital in a humanitarian supply chain.

In Layton’s (2007) definition of marketing systems, the network is created to provide a response to customer demand. When overlapped with IHA, there are now customers at both ends of the chain and two sets of customer demand: the donor who wants to help and the distant other in need of aid. Consumption happens at both ends of the process of delivering aid by both the donor and the aid recipient. While there is no link between the two actors to indicate a direct structural transfer, there is a relationship between the two that is influenced by individual and cross-national differences. Neither the IHA nor the marketing systems approaches take these individual or cross-national differences into account, which influence donor behavior, and the structural view could be expanded by looking at these individual differences. Furthermore, while we may consider the donor and the aid recipient to share participation in this economic exchange, the relationship may also be unidirectional as the donor care where their financial contribution goes but the aid recipient may not care where the aid comes from. Furthermore, the aid recipient's lack of free choice to accept aid goes beyond a traditional marketing analysis of inelastic goods and challenges.

An exploration of the similarities and differences between traditional marketing systems and IHA highlights a gap in our knowledge and an opportunity to advance and expand theory in both bodies of literature.

The IHA system is also marked by unpredictable demand patterns, long durations, destabilized infrastructure, often high and life-threatening stakes, and need for a quick 
response (Beamon and Kotleba 2006; Cassidy 2003; Long and Wood 1995). Where traditional marketing systems look to increase profits, the IHA system's goal is to alleviate the suffering of vulnerable people (Thomas and Kopczak 2005). Success in this market may be measured by growth in the number of customers receiving aid but ultimate success would be if the market was never required in the first place.

\section{Literature Review}

In this review, we first discuss the existing literature and theoretical underpinnings of the 'distant other' literature, then briefly review highlights of the research on 'distance' emerging from the international business (IB) and international marketing (IM) literature, and finally integrate them to develop four propositions concerning how psychic distance might influence the giving to distant others; and thus, represents an unintended bias in the IHA system.

\section{Historical Background}

Questions on the issue of the treatment and care of distant others have been asked for centuries. Philosophers like Aristotle, Diderot, Balzac and Adam Smith believed that distance was tied to compassion and that we should care more about those close to us and less about those further away (Kennedy 2009). The argument is that humans have a natural limit to their capacity for empathy and thus is it unrealistic to expect people to care for distant others (Peterson 2015). However, much of this thought needs to be placed in the proper historical context and was expounded when societies existed on a much smaller scale and the care for outsiders was limited to codes of hospitality (Smith 1998). In these cases, perception of distance was tied primarily to geography. From a moral point of view, Singer (1972) ignited the contemporary philosophical debate about international moral obligations and argued that people are as much obliged to help a distant other in need as to someone in need close to them. He famously said, "It makes no moral difference whether the person I help is a 
neighbor's child ten yards from me or a Bengali whose name I shall never know, ten thousand miles away” (Singer 1972, p.231). The moral philosopher would focus on what one ought to do and not on what one was capable of doing or likely to do. For Singer, distance in any conceptualization was insufficient to deny care. The implication being that the reason that 'care for distant others' is often ignored is due to an individual's inability to provide such care.

The Lisbon earthquake of 1755 was a seminal moment in human imagination and concern for distant others as it "marked one of the first times subjects were faced with a barrage of representations of distant suffering, 'snapshots' that elicited an imaginative and affective engagement with strangers at great distance” (Sliwinski 2009, p.31). Pamphlets of eyewitness accounts with both textual and visual representations were quickly produced and sold throughout Europe and the New World (Larsen 2006; Sliwinski 2009), “where subjects became spectators faced with the ethical and political implications regarding distant suffering” (Sliwinski 2009, p.31). It goes without saying that much has changed since 1755 and that globalization and technology have altered the "spatial organization of human life" (Smith 1998, p.21) and changed the ways in which people can interact with strangers, both near and far. Perceptions of geographic, cultural, and social distance are being altered. An individual's circle of interaction is forever expanding where technology facilitates both the ability to reach the distant other as well as illustrate their plight (Chatterjee 2004).

\section{Imagery in News and Advertising}

Both the news and charity marketing can visually and graphically bring the cause of the distant other to the attention of viewers and potential donors to the benefit of improved television network ratings as well as aid agencies increased income (Silk 2000). In doing so, they have been accused of promoting 'development porn’ (Mittelman and Neilson 2011; 
Neilson and Mittelman 2012; Tanguy 2003) and the 'commodification of suffering' (Kennedy 2009); portraying images of helpless and hopeless parents and very ill, starving, crying semi-clad children with distended bellies and 'flies on eyes' in an attempt to address the social and cultural distance between donors and aid recipients. Both powerful terms represent the usually unsuccessful attempt to balance the need to create awareness and communicate information about the distant other on one hand and the ethics of representation on the other (Kennedy 2009). The imagery used has been accused of being patronizing, demeaning, and even harmful towards those they wish to help.

The study of donor responses to the images of the distant other can reveal insight into donor's perceptions of justice, need, and cultural differences (Radley and Kennedy 1997). For instance, Radley and Kennedy (1997) examined the images used in aid-advertisements and observed that negative and depressing images were expected to motivate giving more than positive images. Additionally, they find that gaze plays an important role in the success of a fundraising advertisement with direct eye contact eliciting the greatest response from donors (Radley and Kennedy 1997). This is supported by Maddox (1993, p.86) who argues that direct gaze into the eyes of a potential donor represents "a demand which is very explicit: send money now”. Both Maddox (1993) and Radley and Kennedy (1997) find that the message "these people need help" must be literally portrayed for it to be acknowledged by the reader.

Hansen, et al. (2014) found that the most important recipient country characteristic for donors on average is hunger and malnutrition, followed by child mortality, quality of infrastructure, income per capita, and, least importantly, ties to the donor's home country. Cavanaugh, Bettman and Luce (2015) examine the influence of emotions used in the marketing of prosocial consumption and charitable giving such as love, hope, pride, and compassion have important influences on consumers (e.g. Belk and Coon 1993; Cavanaugh 
et al. 2011; MacInnis and De Mello 2005, Small and Verrochi 2009). They find that only love, defined as "feelings of warmth and affection toward platonic others (i.e., family and friends) in close, non-sexual relationships” (Cavanaugh et al. 2015, p.9) enhances giving aimed at distant others as love changes the boundary of caring and concern while other positive emotions do not have the same impact (Cavanaugh et al. 2015).

Other internal factors that influence the intention to donate to distant others include: one’s own well-being (Aaker and Akutsu 2009), the feelings of emotional intensity produced by humanitarian crises (Huber et al. 2011), and explicit responsibility for a single distant other (Cryder and Loewenstein 2012). While some external factors that influence charitable giving to distant others include the number of fatalities (Evangelidis and Van den Bergh 2013) and identifiable information of victims (Kogut and Ritov 2007; Small and Loewenstein 2003). For media agencies, these kinds of images of distant others represent 'news values' (Cottle 2013; Galtung and Ruge 1965; Joye 2010; Sood, Stockdale, and Rogers 1987), which necessitates dramatic impact, scale, exoticism, stereotyping of others and abnormality (Silk 2000). The nature of news coverage necessitates that images and portrayals of distant others usually occurs only when 'something' happens, like a major disaster. The coverage and reporting of disasters is often so immediate and focused on death and destruction that the broader socio-political and economic context is often ignored (Joye 2010). This in turn diverts attention from the root causes of poverty and "from issues of justice and basic human rights toward values of charity and pity - with an associated reinforcement of the belief that the North is superior - full of generous givers who can "cure” poverty through aid - and that the South is helpless and powerless" (Goldfinger 2006; as cited in Mittelman and Neilson 2011, p. 375). The reinforcement of the idea of the dependence of the distant other on the developed world ignores not only the idea of self-sufficiency but also the dependency of 
developed countries on developing countries for many raw materials and affordable labor (Silk 2000).

Proponents of such an approach could argue that despite the faults in this kind of representation, that there is a positive net effect in that they expedite a rapid charitable response to major disasters (Silk 2000), often motivated by guilt. Conversely, opponents suggest that the ethical objections to representation of the needs of distant others are extensive where distant others are presented as passive victims and "such simplistic messages foster racist stereotypes, strip entire peoples of their dignity and encourage prejudice” (Sankore 2005) under the guise of 'news value' or advertising effectiveness and outweigh the benefits (Goldfinger 2006; Sankore 2005).

Research on motivations is mixed when it comes to the effectiveness of guilt appeals and the net benefit. While some studies have found that guilt arousal is positively related to the intention to donate (e.g. Hibbert et al. 2007), others have found that a more positive approach will induce giving because of the good feeling the donor is left with (e.g. Silk 2000). A third result, "the Inverted-U” (Bennett 1996), suggests that donor will accept the intensity of a guilt appeal only to a certain point where acceptance will eventually level off and then fall off (e.g. Coulter and Pinto 1995). The model suggests that donor responses are subject to diminishing returns with respect to the level of guilt used or, that is, there is an initial acceptance and increase in attention by donor but that too much guilt will subsequently lead to aversion (Hibbert et al. 2007). Aid organizations rely upon wealthy, Western donor reaction to strong images of the distant other "whose plight seems unjustifiable given our own surplus of resources” (Wenar 2003, p.285). Wenar (2003) contends that this guilt reaction is a result of the activation of a donor's moral concern faced with the need to justify their own action (or inaction) to distant others. These findings, focused on the effectiveness of the campaign, fail to address the possible ideological outcomes of such a portrayal of the 
distant other and make a teleological approach, where actions are judged as morally right based on their consequences, difficult to encapsulate.

The marketing and fundraising campaigns must balance the 'correct' representation of the distant other in their fundraising appeals while also generating the greatest amount of possible donations (Breeze and Dean 2012). Internal documents from one aid organization, PLAN, indicate that this is an issue that development professionals have been struggling with since the 1950's (Mittelman and Neilson 2011). The ethical debate centers on the tension between use of inappropriate and often negative images of the distant other and the goal of maximizing fundraising for the organizations with which they would provide the necessary social programs to help the distant other. The choice between positive images which generate little fundraising and negative images which generate ample support is an ethical dilemma for every organization. Attempts to produce positive or 'good news' campaigns for overseas aid have resulted in negligible donations (Ramrayka 2001).

While there does not seem to be a general agreement in the literature about the extent to which distance should matter ethically, there appears to be a consensus that distance, in practice, influences charitable giving behavior such that a donor is more likely to help a close neighbor than a distant stranger (Guéguen, Lamy, and Fischer-Lokou 2018; Kennedy 2009; Polonsky, Shelly, and Voola 2002; Small and Simonsohn 2008). Simultaneously, within the charitable giving literature, less focus has been given to the distant other relative to 'closer' causes and this assumption that physical distance reduces the intention to donate lacks rigorous investigation (Bajde 2009; Guéguen, Lamy, and Fischer-Lokou 2018).

\section{Donor Behavior}

The donor behavior research has primarily addressed two broad areas: donor motivation (e.g. Basil, Ridgway, and Basil 2008; Bekkers and Wiepking 2010; Guy and Patton 1988; 
Huhmann and Brotherton 1997; Sargeant, West, and Ford 2004) and general determinants and outcomes of charitable giving (e.g. Bendapudi, Singh, and Bendapudi 1996, Burnett and Wood 1988; Ranganathan and Henley 2008; Sargeant and Woodliffe 2007; Webb, Green, and Brashear 2000). While there is no finite list or agreed upon model, the charitable giving literature has identified numerous influences on giving intentions including altruism (e.g. Bendapudi et al. 1996), attitude toward financial donations (e.g. Smith and McSweeney 1997), attitude toward helping others (e.g. Webb et al. 2000), attitude towards charities (e.g. Webb et al. 2000), desire to make a difference (e.g. Duncan 2004), diaspora affiliation (e.g. Brinkerhopff 2008), egoism (e.g. Harbaugh 1998), empathy (e.g. Small and Simonsohn 2008), guilt (e.g. Huhmann and Brotherton 1997), past behavior (e.g. Smith and McSweeney 1997), perceived ability to donate (e.g. Smith and McSweeney 1997), prestige (e.g. Sargeant and Woodliffe 2007), religious obligation (e.g. Hall et al. 2009), social justice theory (e.g. Bendapudi et al. 1996), sympathy (e.g. Small and Simonsohn 2008), and tax benefit (e.g. Sargeant and Woodliffe 2007).

Extant literature posits that individuals are often drawn to help others perceived as similar (e.g. Bekkers 2010; Colaizzi, Williams, and Kayson 1984; Sargeant 1999). Similarity/attraction theory proposes that the more similar our attitudes, beliefs and valued characteristics are to those of others, the more likely it is that one will be attracted to them (Byrne 1969). Studies have demonstrated that similarity effects on helping behavior involved situations in which parties involved had direct, face-to-face interactions (Burger et al. 2001; Garner 2005; Jiang et al. 2010). However, with respect to giving to distant others, charitable appeals do not involve face-to-face contact as most of the communication is done through the charity and their advertising.

Imagery and text in media and advertising is used to communicate traits of the distant other to a potential donor, increase awareness of their plight, and help to catalyze charitable 
contributions. When it comes to charitable giving to distant others, there is a general sense in the literature that “distance” matters (Bajde 2009; Kennedy 2009; von Engelhardt and Jansz 2015). While there is no established definition of distant others, in the context of charitable giving, we offer the following definition of the distant others as persons unknown to the donor who live in another country. The two essential elements in defining distant others are that the beneficiary is a stranger to the donor and that they reside in different countries. Driven by questions about why charitable donors make the choices they do in supporting certain distant other, this study examines the role of distance in charitable giving to distant others, and in doing so, draws upon the concept of psychic distance from the IB literature

\section{Psychic Distance and the IB \& IM Literatures}

Within the international business and international marketing literatures, the term of distance is generally used as a metaphor for cross-national differences and is arguably one of the most prominent concepts in the international business literature over the last 40 years (Prime, Obadia, and Vida 2009; Sousa and Bradley 2006). Indeed, Zaheer, Schomaker and Nachum (2012, p. 19) go as far as claiming that "essentially international management is the management of distance.” Within this stream of literature, there are several overlapping forms of distance, such as cultural distance (Kogut and Singh 1988), institutional distance (Kostova and Zaheer 1999) and cross-national distance (Berry, Guillen, and Zhou 2010); however, the concept of psychic distance is arguable the oldest and broadest of these constructs. The term was originally coined as an afterthought by Beckerman (1956) to explain unusual patterns of intra-European trade. In essence, a substantial portion of trade within Europe appeared to defy classic trade theory, which was based on the concept of comparative advantage (Ricardo 1817) and minimizing transportation costs and trade barriers. In Beckerman's opinion, a substantial portion of the European trade appeared to be related more to social connections; and thus, he coined the term psychic distance as a label 
for the phenomena.

Interestingly, subsequent to Beckerman's (1956) coining of the term psychic distance, the concept lay largely dormant for two decades until a group of researchers in Uppsala (Johanson and Vahlne 1977; Johanson and Wiedersheim-Paul 1975) embraced it in an effort to explain the gradual pattern of internationalization that they had observed amongst Scandinavian firms. In the now famous Uppsala Internationalization Process Model (Johanson and Vahlne 1977), which eventually became the most highly cited model within IB, psychic distance is considered to be both a key driver of which foreign markets a firm choses to enter initially (i.e. firms tend to begin in psychically close markets and then gradually progress on to more psychically distant markets), and a key driver of entry mode choice (i.e. firms will tend to entry more distant market using lower commitment entry modes and only progress to higher modes once the firm has gained more experience). For example, Swedish firms will tend to enter the Finnish market long before they choose to enter the German or UK markets despite the latter two being substantially larger. Moreover, when they do enter more distant markets, they are more likely to use a lower commitment mode, such as an alliance with a local distributor, rather than a higher commitment mode such as a whollyowned subsidiary.

In the process of developing the Uppsala model, Johanson and Vahlne (1977, p. 24) also proposed a more precise definition of psychic distance as the "sum of factors preventing the flow of information from and to the market. Examples are differences in language, education, business practices, culture, and industrial development". Since that time, the concept of psychic distance has been broadened even further by expanding the number of underlying dimensions, such as including differences in religion and past colonial ties (Dow and Karunaratna 2006), in terms of the assumptions and biases in its measurement (Shenkar 2001), and by elaborating on the underlying mechanisms. In particular, subsequent 
researchers have emphasized that psychic distance is not only about factors that prevent the flow of information, but also about the ability to accurately interpret that information (Carlson 1974; Håkanson and Ambos 2010). In addition to that, psychic distance and its underlying dimensions have been subsequently used to predict an even wider range of international behaviors and outcomes ranging from export performance (Griffith and Dimitrova 2014), foreign subsidiary performance (Dikova 2009), adaptation in foreign markets (Dow 2001), international technology transfers (Castellani, Jimenez, and Zanfei 2013), exporter-importer relationships (Durand et al. 2016), the ownership structure of foreign acquisitions (Cuypers, Ertug, and Hennart 2015), foreign direct investment (Blomkvist and Drogendijk 2013; Jimenez and de la Fuente 2016), international new venture creation (Harms and Schiele 2012), tourism (Ahn and McKercher 2015; Bi and Lehto 2018), consumer behavior issues (Safari et al. 2013), the sharing and transfer of international HRM practices (Boyacigiller 1990) and the spread of corporate social responsibility (Campbell, Eden, and Miller 2012) .

Up until the mid-2000s, the dominant approach to measuring psychic distance was to measure it in terms of an index of national cultural dimensions based on the work of Hofstede (1980), an approach popularized by Kogut and Singh (1988); however, over the past decade two new trends have emerged. One of these trends is to continue with exogenous measures of national differences, or what Dow and Karunaratna (2006) refer to as psychic distance stimuli, but to expand the range of metrics beyond Hofstede's dimensions of national culture (Berry et al. 2010; Brewer 2007; Dow and Karunaratna 2006). This approach has the benefit of allowing systematic comparison of a wide range of countries on a comparable basis and allows researchers to explore the impact of various underlying dimensions (or stimuli). The second trend, an alternative approach, is to measure psychic distance in terms of the overall perceptions of the actual decision-maker (Håkanson et al. 2016; Sousa and Bradley 2006). 
Psychic distance stimuli are in effect the antecedents of perceptions of psychic distance (Dow 2017; Dow and Karunaratna 2006; Dow and Larimo 2009). Håkanson and Ambos (2010) in particular argue that this perceptual approach to psychic distance recognizes, at least implicitly, that individuals may differ in respect of their perceptions of foreign countries. Whether it is familial heritage, personal travel, academic exchange or other international experiences, understanding and awareness of other cultures and countries will inevitably differ between individuals (Dichtl et al. 1984). As Shenkar (2001) points out, in many countries it may be inappropriate to assume homogeneity or stability in factors such as language, ethnicity, religion, and education across a single country. This led Dow and Karunaratna (2006, p. 579) to conclude that "psychic distance should ideally be measured by the perceptions of the decision-maker at the time the decision is made”.

In more recent times, and arguably of more relevance to the IHA situation, some researchers (e.g. Dow 2017; Dow et al. 2016; Durand et al. 2016; Horner et al. 2016) have also begun to acknowledge that psychic distance, whether it is measured in terms of the perceptions of a decision-maker or in terms of the national-level differences, may represent more than just what one might consider 'direct' barriers to effective communication (i.e. an inability to understand one another). There is a long history in social psychology literature of acknowledging that differences across groups of people can subtly influence how they interact and react to one another. For example, research on Byrne's (1971) SimilarityAttraction Paradigm, Tajfel and Turner's (1986) Social Identity Theory, and ingroupoutgroups biases (Brewer 1979; Brewer 1999) demonstrate that people tend to favor others who are more like themselves, or who are in the same group that they identify with. These biases extend to more favorable character judgments and the attributions they make about other people, their level of trust in them (Thomas and Ravlin 1995), and even how generous they are to others (Billig and Tajfel 1973; Brewer and Kramer 1985). These more subtle and 
indirect aspects of psychic distance are particularly relevant in the IHA context given that donors and aid recipients rarely have direct communication with one another.

In many respects, this latter development brings the concept of psychic distance much closer to the related concept of 'social distance' (Bogardus 1933). The concept of social distance was first proposed by Park (1924) and is typically used to measure 'prejudice' (Wark \& Galliher 2007); although at its core, it too builds on social psychology concepts such as Social Identity Theory, the Similarity Attraction Paradigm and ingroup-outgroup biases; and concerns about how people respond and interact to others who are different. In that sense social distance has very strongly parallels with our use of psychic distance. However, there is also one critical operational distinction between these two forms of distance. Specifically, psychic distance typically measures the magnitude of the differences between particular groups, with no a priori bias in terms of its impact on how the groups interact. The related Uppsala model (Johanson \& Vahlne 1977), which popularized the concept of psychic distance, may predict a negative impact, but the construct itself is typically measured independent of any such relationship. This is in strong contrast to social distance, which is typically measured in terms of the degree to which the various groups are willing to interact.

The literature on distant others and IHA examines the two opposing positions: that we should care about distant others in need the same way as we do to those close by or we should care more about those close to us than those far away. In exploring caring for the distant others, issues emerged around the portrayal of distant others in advertising and the media including the balance between transmitting information and 'news value', the promotion of stereotypes, the lack of context in reporting, the manipulation of viewers and donors with feelings of guilt, and that aid organizations need to balance correctness with need for fundraising. 
However, there is still much to be learned about charitable giving to distant others in IHA. The literature to date has also focused almost exclusively on donor characteristics while ignoring the diversity of the distant others and the impact of this diversity on the donor and donor attitudes. The distant other is portrayed as a homogenous, generic individual in need. For this reason, research must consider not only the attitudes and intentions of the donor but also the characteristics of the distant other and, subsequently, the fit between the donor and the distant other. This gap in the literature is the starting point of this study as the fit between donors and distant others in IHA is explored using the concept of psychic distance.

\section{Psychic Distance in International Humanitarian Aid}

While, as discussed above, psychic distance has been used in IB research for decades to investigate a plethora of issues, the application of the concepts of psychic distance in relation to marketing, marketing systems, and charitable donor behavior has been left unexplored. Factors such as geographic distance, cultural distance, linguistic and religious differences, differences in economic, education and political systems, and colonial ties, which have played such an important role in IB research, have not to our knowledge been examined in any of these literatures.

In addition to the aforementioned psychic distance stimuli, we add here an additional factor - differences in race, specifically differences between the race of the donor and the race of the distant other. While this factor has not been traditionally used in the IB and IM literature, a small number of recent papers in the economics literature (Giuliano et al. 2014; Spolaore and Wacziarg 2015) have begun incorporating it in the trade models via genetic data. Moreover, we argue that with respect to the Social Identity Theory and ingroupoutgroup aspects of distance, differences in race may be very relevant. Figure 2 illustrates our baseline model of the relationship. 
Figure 2: The Role of Psychic Distance in IHA

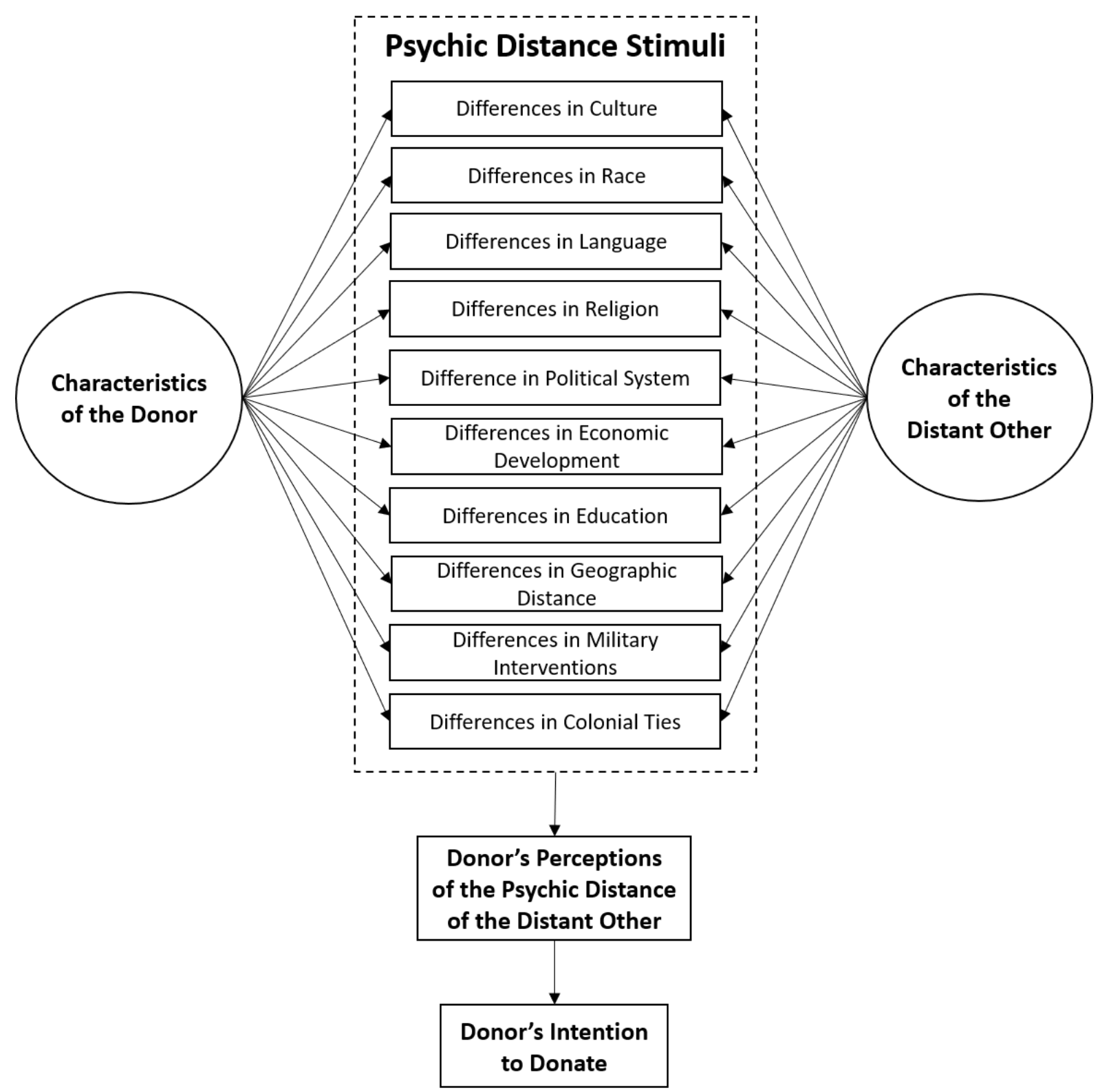

With online giving becoming more and more prevalent, the international reach of both small, local organizations searching for international donors and large multinational organizations looking to support projects in distant countries, the influence of psychic distance needs to be considered as it represents a potentially substantial and unintended bias in the IHA system. The application of these concepts can lay some groundwork for further study. 
As a first step, our working definition of psychic distance needs to be modified slightly to reflect the fact that (i) we are focusing on a different set of stakeholders, and (ii) it is less about the disruption of direct communication between two parties, and more about how cross-national differences may distortion and bias one party's understanding of, and inferences about a distant country, and the potential aid recipients within that country. As a result, we propose that with respect to charitable giving, psychic distance is the sum of factors, such as differences in culture, race, language, religion, political systems, levels of economic development and education between a potential donor and potential aid recipients (and the country they live in), that influence the donor's understanding of and assumptions about the potential aid recipient; and thus, influence their willingness to donate to that distant other'.

In light of this definition, our first contention is that, in general, the greater the differences between a donor and the country of a distant other, the more difficult it will be for the donor to accurately understand and assess the distant country, its context, and the needs of people in that country. This may lead to greater uncertainty about the other country, negative attributions about the people in that country, and a lower level of trust and connection between the donor and the potential recipients. In turn, these factors are likely to reduce the probability of the donor agreeing to contribute towards the potential recipients. As discussed in the preceding section, these arguments are built both on the classic psychic distance literature as per the Johanson and Vahlne (1977) definition of psychic distance, and on the large body of research in social psychology beginning with the seminal work of researchers such as Byrne (1961) and Tajfel (1974). This work and subsequent studies have found that even minor differences between groups of people can evoke in-group / out-group behavior; and thus, like and favor people who are more similar to themselves Byrne (1971), trust them 
more (Billig and Tajfel 1973), and make more favorable attributions about them (Thomas and Ravlin 1995). Thus, our first two propositions are:

Proposition 1: In terms of giving to distant others, larger psychic distances - measured in terms of the various psychic distance stimuli (e.g. differences in culture, race, language, religion, political systems, levels of economic development and education) between the potential donor and recipient - will result in a lower probability of a donation occurring.

Proposition 2: This negative relationship between psychic distance and the probability of a donation, proposed above, will be meditated by (i) the degree to which the potential donor attributes to the recipient positive characteristics, such as trustworthiness and friendliness, and (ii) the degree to which the potential donor attributes to the recipient a degree of blame or responsibility for their 'state of need'.

Notwithstanding the preceding arguments and propositions about how a broad range of cross-national differences, or psychic distance stimuli, may evoke negative sentiments within a potential donor; there are reasons to believe that not all stimuli will have the same strength of impact. The reasons for such variation broadly fall into two categories. First, not all types of differences are equally salient to a donor, particularly when donor decisions typically do not involve any direct contact with the potential recipient, or any visitation to the country in question. In this respect, the application of the concept of psychic distance to charitable giving is subtly different to its application in international business setting where prior due diligence and at least some level of pre-decision investigation is more typical. We argue here that relative to other forms of psychic distance stimuli, differences in race, language and religion are arguably the most salient; thus, we would expect them to have a 
stronger impact. In contrast, factors such as the Hofstede-based cultural distance dimensions (Kogut and Singh 1988) are likely to have a lesser impact as without any direct contact the donors are less likely to be aware of and thus affected by the differences.

The second reason that the negative impact of some forms of psychic distance stimuli may be weaker is that some types of differences may invoke a degree of existential guilt, a factor already acknowledged within the charitable giving literature (Huhmann and Brotherton 1997). This is particularly likely to occur with respect to differences in economic development and differences in political systems (specifically for differences in the degree of democracy), where at least from a Western perspective one end of the spectrum is considered more desirable and individuals are typically considered 'blameless' in terms of the situation they are in. A priori it is not clear whether the positive effects of existential guilt might be greater than the negative effects described in proposition 1 , thereby reversing the direction of the overall relationship, but there is a clear argument that they may reduce the overall magnitude of the negative effects predicted in Proposition 1. As a result, our third proposition is as follows:

Proposition 3: The strength of the negative relationship proposed earlier between the various dimensions of psychic distance stimuli and the probability of a donation will vary depending on (i) the salience of the dimension (e.g. some cross-national dimensions such a differences in language and religion are more salient than others), and (ii) the degree to which the dimension is likely to evoke empathy/sympathy/guilt in the donor (e.g. differences in levels of economic development is more likely to evoke sympathy than differences in language).

The other factor which may influence or moderate the strength of the relationship put 
forward in Proposition 1 is the nature of the event that created the potential recipient's need. This too is an issue that has already been reflected in the charitable giving literature through the work of Zagefka et al. (2011). In cases where the need is generated by events such as a natural disaster - i.e. a situation where the potential recipient has no power over the event and thus cannot carry any blame - Zagefka et al. (2011) found that donors were more likely to donate funds. In contrast, for human generated events, such as wars, donors were less likely to donate funds. This issue is very likely to moderate the 'blame' portion of the direct effect of psychic distance. In human generated disasters, the negative impact of psychic distance that is related to the donor attributing greater blame on the potential recipient essentially has a vehicle through which it can act. Thus, the negative effect put forward in Proposition 1 is likely to be stronger. Conversely, for needs generated by natural disasters, the potential for attributing blame to the recipient is minimal. As a result, our fourth and final proposition is worded as follows:

Proposition 4: The negative relationship between psychic distance stimuli and the probability of a donation proposed earlier will be moderated by the nature of the event that created the recipient's need. For example, difficult to predict nature disasters will weaken the relationship, whereas human generated events such as wars will strengthen the relationship.

\section{Discussion}

The purpose of this paper was to begin an investigation into the role of marketing systems in international humanitarian aid by focusing on charitable giving to distant others and the application of the psychic distance concept as a potential bias in that system. While a call to action brought about by a catastrophe exists along with the necessary supply chain and supporting actors, without the donor's provision of financial aid, this marketing system 
cannot operate. It is imperative that a better understanding of donor activity, behavior and motivation be developed. The introduction of this paper highlighted a large discrepancy in Canadian donor behavior toward victims of natural disasters in Haiti and Pakistan. An examination of many of the psychic distance stimuli may help explain the differences in donor generosity and show that Canada has less psychic distance with Haiti than it does with Pakistan (see Table 1). In addition to being closer geographically to Canada, Haiti and Canada have shared colonial ties to France, resulting in linguistic and religious similarities. While Canada and Pakistan are both members of the Commonwealth, they do not share the same linguistic and religious similarities. Furthermore, the Canadian military and peacekeepers have served in Haiti on several occasions as a part of United Nations missions while the Canadian military has not been involved in Pakistan. Overall, Haiti is closer than Pakistan to Canada on five of the ten psychic distance stimuli and equally distant on the other five stimuli. This would, anecdotally, support Proposition 1 that a larger psychic distance would decrease the probability of donation.

Table 1: Psychic Distance Comparison

\begin{tabular}{|c|c|c|c|}
\hline & Canada (from) & Haiti (to) & Pakistan (to) \\
\hline \multicolumn{4}{|l|}{ Differences in Culture $^{1}$} \\
\hline Individualism & high & medium & low \\
\hline Uncertainty Avoidance & low & very low & high \\
\hline Power distance & low & low & medium \\
\hline Masculinity & medium & high & medium \\
\hline Net Euclidean distance & - & medium (1.68) & high (2.55) \\
\hline & & CLOSER & FURTHER \\
\hline $\begin{array}{l}\text { Differences in } \\
\text { Race }^{2}\end{array}$ & $\begin{array}{l}\text { Primarily Anglo-Saxon, but } \\
\text { high level of diversity }\end{array}$ & $\begin{array}{l}\text { Afro-Caribbean } \\
\text { EQUAL DISTANCE }\end{array}$ & $\begin{array}{l}\text { South Asian } \\
\text { EQUAL DISTANCE }\end{array}$ \\
\hline $\begin{array}{l}\text { Differences in } \\
\text { Language }^{3}\end{array}$ & $\begin{array}{l}\text { English \& French both } \\
\text { official languages; French } \\
\text { 22\%, Punjabi 1.2\% }\end{array}$ & $\begin{array}{l}\text { Haitian Creole, and } \\
\text { French } 40 \% \\
\text { CLOSER }\end{array}$ & $\begin{array}{l}\text { Punjabi, Sindhi, and } \\
\text { Urdu } \\
\text { FURTHER }\end{array}$ \\
\hline
\end{tabular}




\begin{tabular}{|c|c|c|c|}
\hline $\begin{array}{l}\text { Differences in } \\
\text { Religion }^{4}\end{array}$ & $\begin{array}{l}\text { Roman Catholic 39\%, } \\
\text { Protestant 20.3\%, Muslim } \\
3.2 \%\end{array}$ & $\begin{array}{l}\text { Roman Catholic 54.7\%, } \\
\text { Protestant 28.5\% } \\
\text { CLOSER }\end{array}$ & $\begin{array}{l}\text { Muslim 96\% } \\
\text { FURTHER }\end{array}$ \\
\hline $\begin{array}{l}\text { Differences in } \\
\text { Political System }^{5}\end{array}$ & $\begin{array}{l}\text { Top quartile in the world } \\
\text { for democratic freedom } \\
\text { (tied for highest rating) }\end{array}$ & $\begin{array}{l}\text { Not very democratic, } \\
\text { unstable, violent. Ranked } \\
144^{\text {th }} \text { out of } 210 \text { countries } \\
\text { EQUAL DISTANCE }\end{array}$ & $\begin{array}{l}\text { Not very democratic, } \\
\text { unstable, violent. } \\
\text { Ranked } 140^{\text {th }} \text { out of } 210 \\
\text { countries } \\
\text { EQUAL DISTANCE }\end{array}$ \\
\hline $\begin{array}{l}\text { Differences in } \\
\text { Economic Development }{ }^{6}\end{array}$ & $\begin{array}{l}15^{\text {th }} \text { out of } 200 \text { in } \\
\text { GDP pc (US\$45,000) }\end{array}$ & $\begin{array}{l}124^{\text {th }} \text { out of } 200 \text { in GDP } \\
\text { pc (US\$765) } \\
\text { EQUAL DISTANCE }\end{array}$ & $\begin{array}{l}110^{\text {th }} \text { out of } 200 \text { in GDP } \\
\text { pc (US\$1,547) } \\
\text { EQUAL DISTANCE }\end{array}$ \\
\hline $\begin{array}{l}\text { Differences in } \\
\text { Education }^{7}\end{array}$ & $\begin{array}{l}\text { High level of literacy. } \\
(99 \%)\end{array}$ & $\begin{array}{l}\text { Low level of literacy. } \\
(45 \%) \\
\text { EQUAL DISTANCE }\end{array}$ & $\begin{array}{l}\text { Low level of literacy. } \\
(57 \%) \\
\text { EQUAL DISTANCE }\end{array}$ \\
\hline Geographic Distance $^{8}$ & - & $\begin{array}{l}\text { 5,000 km } \\
\text { CLOSER }\end{array}$ & $\begin{array}{l}10400 \mathrm{~km} \\
\text { FURTHER }\end{array}$ \\
\hline Military Interventions ${ }^{9}$ & - & $\begin{array}{l}\text { Multiple } \\
\text { CLOSER }\end{array}$ & $\begin{array}{l}\text { Never } \\
\text { FURTHER }\end{array}$ \\
\hline Colonial Ties $^{10}$ & - & $\begin{array}{l}\text { Shared } \\
\text { EQUAL DISTANCE }\end{array}$ & $\begin{array}{l}\text { Shared } \\
\text { EQUAL DISTANCE }\end{array}$ \\
\hline
\end{tabular}

Hofstede (2001); 2, 3, 4. Economist Intelligence Unit (2018); 5. Freedom House (2018); 6. World Bank (2018); 7. UNESCO (2018); 8. distanacefromto.net (2018); 9. National Defense and the Canadian Armed Forces (2018); 10. Aldrich (1996) and The Commonwealth (2018).

While there are sizable populations of both Haitian Canadians and Pakistani Canadians, numerous Haitian Canadians have risen to prominence in Canada as Olympic medalists, professional athletes, award-winning journalists, and politicians including The Right Honourable Michaëlle Jean, who served as Canada’s Governor General, the personal representative of the Queen of England and ceremonial head of the Canadian government. Pakistani Canadians may not be as well known to Canadians. This may contribute to and support Proposition 2 in terms of Canadian views of the trustworthiness and friendliness of Haitians and Pakistanis. 
The differences in the disasters may also influence and vary donor behavior (Propositions 2, 3 \& 4). While both natural disasters, there may be some important difference between earthquakes and floods in terms of the degree of responsibility of those affected (Proposition 2) and the amount of sympathy generated (Proposition 3). Earthquakes, like the one in Haiti in 2010, are sudden and, violent; causing a large number of casualties that necessitates an immediate response and generates sympathy for those affected. Floods, on the other hand, build over a longer period, allowing time for preparation or evacuation and therefore less loss of life and less sympathy, perhaps ultimately resulting in fewer donations. Marketing systems represent a core concept in macromarketing and, as Layton (2007, p. 227) describes, "The effectiveness of a marketing system can be identified in the contribution of the assortments generated by the system to the quality of life of the relevant communities”. IHA represents a complex system of relationships between donors, aid agencies, governments, stakeholders, and beneficiaries where the goal is improved quality of life for the distant others in the face of disaster and tragedy. By applying psychic distance, an improved flow of donations for the betterment of the distant other and a more effective marketing system can be achieved.

With limited past discussion of the IHA system in the macromarketing literature, the exploration and application of psychic distance can help raise the profile of these issues in a macromarketing context. This is the first attempt to consider the elements of psychic distance and explore the role it plays in charitable giving to distant others. This gap exists not only in the study of distant others but, perhaps more importantly and interestingly, in the charitable giving and macromarketing literatures. Factors such as cultural distance, geographic distance, language, colonial ties and military interventions, which have played such an important role in international business research, have not been examined in the charitable giving literature. With online giving becoming more and more prevalent, the international reach of both small, 
local organizations searching for international donors and large multinational organizations looking to support projects in distance countries, the factors of psychic distance need to be considered. The exploration of these concepts in this paper can lay some groundwork for further study not just in IHA but in exploring how else psychic distance could be applied within the study of macromarketing.

While psychic distance has been used in international business research for decades to investigate a plethora of subjects, the application of psychic distance in relation to consumer and donor behavior when giving to charity has been left unexplored. As such, from an IB perspective this paper represents a novel extension and application of one of the most popular constructs in this literature.

\section{Implications for Future Research}

In terms of the implications for future research, and specifically how to test the propositions put forward in this paper, we see three potential avenues for future research. The first avenue of potential research mirrors the anecdote cited in the introduction of this paper concerning the 2010 events in Haiti and Pakistan. One could use major humanitarian disasters, and the associated campaigns to raise funds for relief, as the unit of analysis. The total amount of donations, and/or the number of distinct donors per campaign could act as the criterion variables. The first, third and fourth propositions could then be tested by collecting data on the nature of the events and the people in need. You could control for issues such as the amount of money spent on promoting the campaigns and the size of the target audience. Content analysis of the campaign materials could also be carried out to see whether they emphasize any dimensions related to our propositions.

The main advantage of this approach is that it deals with the actual events of concern and implicitly captures both the behaviors of the people who have chosen to donate and the 
people who have chosen to not donate. However, this approach also has limitations. One limitation is the potential sample size. Fortunately, these events are low in number, but that does limit the statistical power of any analyses. Second, when estimating the distance dimensions using this approach one does not typically have details concerning the donors, other than their country of origin. As a result, you are forced to assume homogeneity across the donor country when in fact it is very likely that the pool of actual donors will be skewed. A third limitation of this approach is that one is not able to explore the second proposition concerning the mediating factors.

A second potential approach to testing the propositions is a more fine-grained analysis of the actual donors. If one or more NGOs are willing to allow access to their donor database, an analysis of donation behavior at the level of the individual could be carried out. Via a possible mail survey, one gathers additional donor attributes. This would resolve the first two limitations of the preceding approach (i.e. resolving the sample size and the assumption of homogeneity), allowing a better investigation of Propositions 1 and 3. In addition to that, interviews with donors could be conducted and content analysis used to explore Proposition 2 (i.e. the mediating factors). The major limitation here is whether major NGO's would allow such access to their databases.

The third potential approach is to borrow a methodology from the fields of social psychology and behavioral economics, and conduct experiments concerning people's donation behaviors. Specifically, one could create mock donation scenarios and manipulate various aspects of the donation process, such as the nature of the distant others (Propositions 1 and 3) and the nature of the event (Proposition 4). As with the second approach, one could also use various techniques for exploring Proposition 2. For example, after a mock decision, the subject could be asked to discuss their thought processes during the decision, or specific instruments could be included to measure the mediating constructs. While the main 
limitation of this approach is that it is not based on actual donation behavior but rather intentions to donate, it does have many positive aspects. As with the second approach it resolves both the issues of statistical power and avoids the need to assume homogeneity across the donors from a given country. In addition to that, experiments allow a far more controlled and fine-grained investigation of issues, which allows one to isolate distinct effects and rule out concerns about the direction of causality, missing variables and spurious correlations (Leung et al. 2005).

The testing of the propositions are not the only implications and areas for future research. As this is an understudied area of scholarship in marketing, there are many more theoretical and practical questions left unanswered in the study of charitable giving to distant others. The exploration of the IHA marketing systems raises further questions about the depiction of distant others and the role that marketing communications can play in increasing or decreasing perceptions of psychic distance. Consequently, it raises ethical questions about the promotion of negative stereotypes to increase fundraising totals, the need to maintain a power imbalance in charity marketing between the donor and the recipient, as well as the potential negative impacts of not featuring some distant others in need because the distance is perceived to be too great.

In closing, we believe that this paper, through the propositions that we have developed and the suggestions for future research, represents an important research agenda. It both highlights the importance of understanding the marketing system related to IHA and identifies a factor that we believe may be a major but subconscious bias in donation behavior - psychic distance. While we have proposed three distinct approaches to testing our propositions, we believe that complex issues such as IHA need to be addressed by a variety of methods. Thus, rather than endorse one particular methodological approach, we encourage researchers a variety of approaches. 


\section{References}

Aaker, Jennifer and Satoshi Akutsu (2009), "Why do people give? The role of identity in giving,” Journal of Consumer Psychology, 19 (3), 267-70.

Ahn, Michael J. and Bob McKercher (2015), "The effect of cultural distance on tourism: A study of international visitors to Hong Kong," Asia Pacific Journal of Tourism Research, 20 (1), 94-113.

Aldrich, Robert (1996), Greater France: A history of French overseas expansion, Macmillan International Higher Education.

Bajde, Domen (2009), "Rethinking the social and cultural dimensions of charitable giving," Consumption, Markets and Culture, 12 (1), 65-84.

Baker, Stacey Menzel (2009), "Vulnerability and resilience in natural disasters: A marketing and public policy perspective,” Journal of Public Policy \& Marketing, 28 (1), 14-23.

Baker, Stacey Menzel, Ronald Paul Hill, Courtney Nations Baker, and John D. Mittelstaedt (2015), “Improvisational provisioning in disaster: the mechanisms and meanings of ad hoc marketing exchange systems in community,” Journal of Macromarketing, 35 (3), 334-52.

Barrios, Andres, Kristine de Valck, Clifford J. Shultz, Olivier Sibai, Katharina C. Husemann, Matthew Maxwell-Smith, and Marius K. Luedicke (2016), “Marketing as a means to transformative social conflict resolution: lessons from transitioning war economies and the Colombian coffee marketing system,” Journal of Public Policy \& Marketing, 35 (2), 185-97.

Basil, Debra, Nancy Ridgway, and Michael Basil (2008), “Guilt and giving: A process model of empathy and efficacy,” Psychology and Marketing, 25 (1), 1-23. 
Beamon, Benita, and Stephen Kotleba (2006), “Inventory modelling for complex emergencies in humanitarian relief operations,” International Journal of Logistics: Research and Applications, 9 (1), 1-18.

Beckerman, Wilfred (1956), “Distance and the pattern of inter-European trade,” The Review of Economics and Statistics, 38 (1), 31-40.

Beigbeder, Yves (1991), The Role and Status of International Humanitarian Volunteers and Organizations: The Right and Duty to Humanitarian Assistance (Vol. 12), Martinus Nijhoff Publishers.

Bekkers, Rene (2010), “George gives to geology Jane: The name letter effect and incidental similarity cues in fundraising," International Journal of Nonprofit and Voluntary Sector Marketing, 15 (2), 172-80.

Bekkers, Rene and Pamala Wiepking (2011), “A literature review of empirical studies of philanthropy: Eight mechanisms that drive charitable giving,” Nonprofit and Voluntary Sector Quarterly, 40 (5), 924-73.

Belk, Russell and Gregory Coon (1993), "Gift giving as agapic love: An alternative to the exchange paradigm based on dating experiences," Journal of Consumer Research, 20 (3), 393-417.

Bendapudi, Neeli, Surendra Singh, and Venkar Bendapudi (1996), “Enhancing helping behavior: An integrative framework for promotion planning,” Journal of Marketing, 60 (3), 33-49.

Bennett, Roger (1996), “Effects of horrific fear appeals on public attitudes towards AIDS,” International Journal of Advertising, 15 (3), 183-202.

Berry, Heather, Mauro Guillen, and Nan Zhou (2010), “An institutional approach to crossnational distance,” Journal of International Business Studies, 41 (9), 1460-80. 
Bi, Juan and Xinran Y. Lehto (2018), "Impact of cultural distance on international destination choices: The case of Chinese outbound travelers,” International Journal of Tourism Research, 20 (1), 50-59.

Billig, Michael and Henri Tajfel (1973), “Social categorization and similarity in intergroup behaviour,” European Journal of Social Psychology, 3 (1), 27-52.

Blomkvist, Katarina. and Rian Drogendijk (2013), “The impact of psychic distance on Chinese outward foreign direct investments,” Management International Review, 53 (5), 659-86.

Bogardus, Emory S. (1933), “A Social Distance Scale,” Journal of Applied Sociology, 17, 265-71.

Boyacigiller, Nakiye (1990), “The role of expatriates in the management of interdependence, complexity and risk in multinational corporations,” Journal of International Business Studies, 21 (3), 357-81.

Breeze, Beth and Jon Dean (2012), "Pictures of me: user views on their representation in homelessness fundraising appeals,” International Journal of Nonprofit and Voluntary Sector Marketing, 17 (2), 132-43.

Brewer, Marilynn (1979), “In-group bias in the minimal intergroup situation: A cognitivemotivational analysis,” Psychological Bulletin, 86 (2), 307.

Brewer, Marilynn (1999), “The psychology of prejudice: Ingroup love and outgroup hate?,” Journal of Social Issues, 55 (3), 429-44.

Brewer, Marilynn and Roderick Kramer (1985), “The psychology of intergroup attitudes and behavior,” Annual Review of Psychology, 36 (1), 219-43. 
Brewer, Paul (2007), “Operationalizing psychic distance: A revised approach,” Journal of International Marketing, 15 (1), 44-66.

Brinkerhoff, Jennifer M (2008), “Diaspora philanthropy in an at-risk society: The case of Coptic orphans in Egypt,” Nonprofit and Voluntary Sector Quarterly, 37 (3), 411-33.

Burger, Jerry, Shelley Soroka, Katrina Gonzago, Emily Murphy, and Emily Somervell (2001) “The effect of fleeting attraction on compliance to requests,” Personality and Social Psychology Bulletin, 27 (12), 1578-86.

Burnett, John and Van Wood (1988), “A proposed model of the donation decision process,” Research in consumer behavior, 3, 1-47.

Byrne, Donn (1961), “Interpersonal attraction and attitude similarities,” Journal of Abnormal and Social Psychology, 62 (3), 713-15.

Byrne, Donn (1969), “Attitudes and attraction,” Advances in Experimental Social Psychology, 4, 35-89.

Byrne, Donn (1971), The Attraction Paradigm. New York: Academic Press.

Campbell, Joanna, Lorraine Eden, and Stewart Miller (2012), “Multinationals and corporate social responsibility in host countries: Does distance matter?,” Journal of International Business Studies, 43 (1), 84-106.

Canadian International Development Platform. (2015). Canada's Foreign Aid, [available at http://cidpnsi.ca].

Carlson, Sune (1974), “International Transmission of Information and the Business Firm,” The Annals of the American Academy of Political and Social Science, 412 (1), 55-63.

Cassidy, William (2003), “A logistics lifeline”, Traffic World, October 27, 1. 
Castellani, Davide, Alfredo Jimenez, and Antonello Zanfei (2013), “How remote are R\&D labs? Distance factors and international innovation activities,” Journal of International Business Studies, 44 (7), 649-75.

Cavanaugh, Lisa, James Bettman, and Mary Frances Luce (2015), “Feeling love and doing more for distant others: Specific positive emotions differentially affect prosocial consumption,” Journal of Marketing Research, 52 (5), 657-73.

Cavanaugh, Lisa, Keisha Cutright, Mary Frances Luce, and James Bettman (2011), “Hope, pride, and processing during optimal and nonoptimal times of day,” Emotion, 11 (1), 38.

Chatterjee, Deen (2004), The ethics of assistance: morality and the distant needy, Cambridge University Press.

Christopher, Martin and Peter Tatham (2014), Humanitarian logistics: Meeting the challenge of preparing for and responding to disasters. Kogan Page Publishers.

Colaizzi, Antoinette, Kim Williams, and Wesley Kayson (1984), "When will people help? The effects of gender, urgency, and location on altruism,” Psychological Reports, 55 (1), 139-42.

Cottle, Simon (2013), “Journalists witnessing disaster: From the calculus of death to the injunction to care,” Journalism Studies, 14 (2), 232-48.

Coulter, Robin and Mary Beth Pinto (1995), “Guilt appeals in advertising: what are their effects?,” Journal of Applied Psychology, 80 (6), 679-705.

Cryder, Cynthia and George Loewenstein (2012), "Responsibility: The tie that binds," Journal of Experimental Social Psychology, 48 (1), 441-45. 
Cuypers, Ilya, Gokhan Ertug, and Jean-Francois Hennart (2015), “The effects of linguistic distance and lingua franca proficiency on the stake taken by acquirers in cross-border acquisitions,” Journal of International Business Studies, 46 (4), 429-42.

Development Initiatives (2017), “Global Humanitarian Assistance Report 2017,” (accessed January 2, 2018), [available at http://devinit.org/].

Dichtl, Erwin, Marius Leibold, H.-G. Koeglmayr, and Stefan Mueller (1984), “The export decision of small and medium-sized firms: A Review,” Management International Review, 24 (2), 49-60.

Dikova, Desislava (2009), "Performance of foreign subsidiaries: Does psychic distance matter?” International Business Review, 18 (1), 38-49.

Distancefromto.net (2018), Distance Between Cities Places On Map, (accessed on July 18, 2018), [available at https://www.distancefromto.net/].

Dow, Douglas (2017), “Are we at a turning point for distance research in international business studies?,” in Progress in International Business Research, Alan Verbeke, R. Tulder, and J. F. Puck, eds., Emerald Publishing Group, 47-68

Dow, Douglas (2001), “The adaptation of host market positioning strategies: Empirical evidence from Australia,” Journal of International Marketing, 9 (3), 41-62.

Dow, Douglas and Amal Karunaratna (2006), “Developing a multidimensional instrument to measure psychic distance stimuli,” Journal of International Business Studies, 37 (5), 575-77.

Dow, Douglas. and Jorma Larimo (2009), “Challenging the conceptualization and measurement of distance and international experience in entry mode choice research,” Journal of International Marketing, 17 (2), 74-98. 
Dow, Douglas, Ilya Cuypers and Gokhan Ertug (2016), “The effects of within-country linguistic and religious diversity on foreign acquisitions,” Journal of International Business Studies, 47 (3), 319-46.

Duncan, Brian (2009), “A theory of impact philanthropy,” Journal of Public Economics, 88 (9), 2159-80

Durand, Aurelia, Ekaterina Turkina, and Matthew Robson (2016), "Psychic distance and country image in exporter-importer relationships," Journal of International Marketing, 24 (3), 31-57.

Economist Intelligence Unit (2018), Country Report, (accessed on July 18, 2018), [available at http://country.eiu.com].

Ernst, Ricardo (2003), “The academic side of commercial logistics and the importance of this special issue,” Forced Migration Review, 18 (1), 5-8.

Evangelidis, Ioannis and Bram Van den Bergh (2013), "The number of fatalities drives disaster aid increasing sensitivity to people in need,” Psychological science, 24 (11), 2226-34.

Freedom House (2018), Freedom in the World 2018 Table of Country Scores, (accessed on July 18, 2018), [available at https://freedomhouse.org/report/freedom-world-2018table-country-scores].

Galloway, Gloria (2012, September 12). What's next for the \$70-million Canadians donated to East Africa. The Globe and Mail. (accessed on August 12, 2017), [available at http://www.theglobeandmail.com/ ].

Galtung, Johan and Mari Holmboe Ruge (1965), “The structure of foreign news the presentation of the Congo, Cuba and Cyprus Crises in four Norwegian newspapers,” Journal of Peace Research, 2 (1), 64-90. 
Garner, Randy (2005), “What's in a name? Persuasion perhaps,"” Journal of Consumer Psychology, 15 (2), 108-16.

Giuliano, Paola., Antonio Spilimbergo, and Giovanni Tonon (2014), “Genetic distance, transportation costs, and trade,” Journal of Economic Geography, 14 (1), 224-25.

Goldfinger, Danielle (2006), "Development pornography: images of the global south,” Artishake, 2 (Spring), 4-5.

Greenhill, Robert (2017, April 10), “Canada is not back when it comes to global aid - it’s far back," The Globe and Mail, (accessed on August 12, 2017), [available at http://www.theglobeandmail.com].

Griffith, David A. and Boryana. V. Dimitrova (2014), "Business and cultural aspects of psychic distance and complementarity of capabilities in export relationships,” Journal of International Marketing, 22 (3), 50-67.

Guéguen, Nicolas, Lubomir Lamy, and Jacques Fischer-Lokou (2018), "Does the sense of the geographic proximity of a requester influence donation? Three evaluations in field studies,” Journal of Human Behavior in the Social Environment, 28(2), 193-203.

Guy, Bonnie and Wesley Patton (1988), “The marketing of altruistic causes: understanding why people help,” Journal of Services Marketing, 2 (1), 5-16.

Håkanson, Lars and Bjorn Ambos (2010), “The antecedents of psychic distance,” Journal of International Management, 16 (3), 195-210.

Håkanson, Lars., Björn Ambos, Anja Schuster, and Ulrich Leicht-Deobald (2016), “The psychology of psychic distance: Antecedents of asymmetric perceptions,” Journal of World Business, 51 (2), 308-18. 
Hall, Michael, David Lasby, Steven Ayer, and William David Gibbons (2009), Caring Canadians, involved Canadians: Highlights from the 2007 Canada Survey of Giving, Volunteering, and Participating, (Catalogue No. 71-542-XPE). Statistics Canada, Ottawa, Canada.

Hansen, Paul, Nicole Kergozou, Stephen Knowles and Paul Thorsnes (2014), “Developing countries in need: Which characteristics appeal most to people when donating money?,” The Journal of Development Studies, 50 (11), 1494-509.

Harbaugh, William T (1998), "What do donations buy? A model of philanthropy based on prestige and warm glow,” Journal of Public Economics, 67 (2), 269-28.

Harms, Rainer and Holger Schiele (2012), “Antecedents and consequences of effectuation and causation in the international new venture creation process," Journal of International Entrepreneurship, 10 (2), 95-116.

Hibbert, Sally, Andrew Smith, Andrea Davies and Fiona Ireland (2007), "Guilt appeals: Persuasion knowledge and charitable giving” Psychology and Marketing, 24 (8), 72342.

Hofstede, Geert (1980), Cultural Consequences: International Differences in Work Related Values. Beverly Hills: Sage Publications.

Hofstede, Geert (2001), Culture's Consequences: Comparing Values, Behaviors, Institutions, and Organizations Across Nations, 2nd ed. Sage, Thousand Oaks, CA.

Höijer, Birgitta (2004), “The discourse of global compassion: The audience and media reporting of human suffering,” Media, Culture and Society, 26 (4), 513-31.

Horner, Steven, Daniel Baack, and Donald Baack (2016), “The role of psychic distance in internationalization strategy evaluations and strategic choices,” Journal of Business Strategies, 33 (1), 17-48. 
Huber, Michaela, Leaf Van Boven, A. Peter McGraw, and Laura Johnson-Graham (2011), "Whom to help? Immediacy bias in judgments and decisions about humanitarian aid," Organizational Behavior and Human Decision Processes, 115 (2), 283-93.

Huhmann, Bruce and Timothy Brotherton (1997), “A content analysis of guilt appeals in popular magazine advertisements,” Journal of Advertising, 26 (2), 35-45.

IUPUI Lilly Family School of Philanthropy (2017), Giving USA 2017: The Annual Report on Philanthropy, Giving USA Foundation.

Jiang, Lan, Joandrea Hoegg, Darren Dahl and Amitava Chattopadhyay (2010), “The persuasive role of incidental similarity on attitudes and purchase intentions in a sales context,” Journal of Consumer Research, 36 (5), 778-91.

Jimenez, Alfredo and David de la Fuente (2016), “Learning from others: The impact of vicarious experience on the psychic distance and FDI relationship,” Management International Review, 56 (5), 633-64.

Johanson, Jan and Jan-Erik Vahlne (1977), "The internationalization process of the firm-A model of knowledge development and increasing foreign commitments,” Journal of International Business Studies, 8 (1), 23-32.

Johanson, Jan and Finn Wiedersheim-Paul (1975), “The internationalization of the firm: Four Swedish cases,” Journal of Management Studies, 12 (October), 305-22.

Joye, Stijn (2010), “News discourses on distant suffering: a Critical Discourse Analysis of the 2003 SARS outbreak,” Discourse and Society, 21 (5), 586-601.

Kaatrud, David, Ramina Samii and Luk van Wassenhove (2003), “UN joint logistics centre: a coordinated response to common humanitarian logistics concerns,” Forced Migration Review, 18 (7), 11-14. 
Kennedy, Dennis (2009) “Selling the distant other: Humanitarianism and imagery—Ethical dilemmas of humanitarian action,” The Journal of Humanitarian Assistance, 28, 1-25.

Kogut, Bruce and Harbir Singh (1988), “The effect of national culture on the choice of entry mode,” Journal of International Business Studies, 19 (3), 411-32.

Kogut, Tehila and Ilana Ritov (2007), ““'One of us”: Outstanding willingness to help save a single identified compatriot," Organizational Behavior and Human Decision Processes, 104 (2), 150-57.

Kostova, Tatiana and Srilata Zaheer (1999), “Organizational legitimacy under conditions of complexity: The Case of the Multinational Enterprise,” Academy of Management Review, 24 (1), 64-81.

Kovács, Gyongyi and Karen Spens (2007), “Humanitarian logistics in disaster relief operations,” International Journal of Physical Distribution and Logistics Management, 37(2), 99-114.

Larsen, Svend Erik (2006), “The Lisbon earthquake and the scientific turn in Kant's philosophy,” European Review, 14 (03), 359-67.

Layton, Roger (2007), “Marketing systems-A core macromarketing concept,” Journal of Macromarketing, 27 (3), 227-42.

Layton, Roger (2015), “Formation, Growth, and Adaptive Change in Marketing Systems,” Journal of Macromarketing, 35 (3), 349-62.

Leung, Kwok, Rabi S. Bhagat, Nancy R. Buchan, Miriam Erez, and Christina B. Gibson (2005), “Culture and international business: Recent advances and their implications for future research,” Journal of International Business Studies, 36 (4), 357-78. 
Long, Douglas and Donald Wood (1995), “The logistics of famine relief,” Journal of Business Logistics, 16 (1), 213-29.

MacInnis, Debrorah and Gustavo De Mello (2005), “The concept of hope and its relevance to product evaluation and choice,” Journal of Marketing, 69 (1), 1-14.

Maddox, Marion (1993), "Ethics and rhetoric of the starving child,” Social semiotics, 3 (1), 71-94.

Mittelman, Robert and Leighann Neilson (2011), "Development porn? Child sponsorship advertisements in the 1970s," Journal of Historical Research in Marketing, 3 (3), 370401.

National Defense and the Canadian Armed Forces (2018), Operations, (accessed on July 18, 2018), [available at http://www.forces.gc.ca/en/operations.page].

Neilson, Leighann and Robert Mittelman (2012), “Ideological outcomes of marketing practices: A critical historical analysis of child sponsorship programs," Research in Consumer Behavior, 14, 9-27.

OECD (2014, August 4). Aid to developing countries rebounds in 2013 to reach an all-time high, (accessed on August 13, 2017), [available at http://www.oecd.org].

OECD (2017, April 11). Development aid rises again in 2016 but flows to poorest countries dip, (accessed on August 13, 2017), [available at http://www.oecd.org].

Oloruntoba, Richard and Richard Gray (2006), “Humanitarian aid: an agile supply chain?,” Supply Chain Management: an international journal, 11 (2), 115-20.

Özdamar, Linet, Ediz Ekinci and Beste Küçükyazici (2004), “Emergency logistics planning in natural disasters,” Annals of operations research, 129 (1), 217-45. 
Park, Robert. E. (1924), “The concept of social distance as applied to the study of racial attitudes and racial relations,” Journal of Applied Sociology, 8 (6), 339-44.

Peterson, Gregory (2015), “Can one love the distant other? Empathy, affiliation, and cosmopolitanism,” Philosophy, Theology and the Sciences, 2 (1), 4-24.

Polonsky, Michael J., Laura Shelley, and Ranjit Voola (2002), “An examination of helping behavior-Some evidence from Australia," Journal of Nonprofit \& Public Sector Marketing, 10 (2), 67-82.

Prime, Nathalie, Claude Obadia, and Irena Vida (2009), "Psychic distance in exporterimporter relationships: A grounded theory approach,” International Business Review, 18 (2), 184-98.

Radley, Alan and Marie Kennedy (1997), “Picturing need: Images of overseas aid and interpretations of cultural difference,” Culture and Psychology, 3 (4), 435-60.

Ramrayka, Liza (2001, June 15), “Charities struggle to find right balance with ad campaigns,” The Guardian, (accessed on August 13, 2017), [available at https://www.theguardian.com/].

Ranganathan, Sampath and Walter Henley (2008), "Determinants of charitable donation intentions: A structural equation model,” International Journal of Nonprofit and Voluntary Sector Marketing, 13 (1), 1-11.

Ranganathan, Sampath, James Loebl and David Radosevich (2012), “Understanding students' responses to university-led charity campaigns: a study of a Haitian earthquake relief campaign,” International Journal of Nonprofit and Voluntary Sector Marketing, 17 (1), 65-74.

Reimann, Kim D (2017). “Up to no good? Recent critics and critiques of NGOs” in Subcontracting Peace, Henry Carey ed., Routledge, London, 37-53. 
Ricardo, David (1817), Principles of Political Economy and Taxation. London.

Saatcioglu, Bige, and Canan Corus (2014), "Poverty and intersectionality: A multidimensional look into the lives of the impoverished," Journal of Macromarketing, 34 (2), 122-32.

Safari, Aswo, Peter Thilenius, and Amjad Hadjikhani (2013), “The impact of psychic distance on consumers' behavior in international online purchasing," Journal of International Consumer Marketing, 25 (4), 234-49.

Sankore, Rotimi (2005), "Behind the Image: Poverty and Development Pornography," Pambazuka News, (accessed on August 13, 2017), [available at http://www.pambazuka.org/governance/behind-image-poverty-and-developmentpornography].

Sargeant, Adrian (1999), “Charitable giving: Towards a model of donor behaviour,” Journal of Marketing Management, 15 (4), 215-38.

Sargeant, Adrian and Lucy Woodliffe (2007), “Gift giving: an interdisciplinary review,” International Journal of Nonprofit and Voluntary Sector Marketing, 12 (4), 275-307.

Sargeant, Adrian, Doug West, and John Ford (2004), “Does perception matter?: an empirical analysis of donor behaviour,” The Service Industries Journal, 24 (6), 19-36.

Shenkar, Oded (2001), “Cultural distance revisited: Towards a more rigorous conceptualization and measurement of cultural differences,” Journal of International Business Studies, 32 (3), 519-36.

Shultz, Clifford J. II (1997), "Improving life quality for the destitute: Contributions from multiple-method fieldwork in war-ravaged transition economies,” Journal of Macromarketing, 17 (1), 56-67. 
Shultz, Clifford J. II (2005), “Some macromarketing thoughts on recent natural and humaninduced disasters,” Journal of Macromarketing, 25 (1), 3-4.

Shultz, Clifford, J. II (2015), “The Ethical Imperative of Constructive Engagement in a World Confounded by the Commons Dilemma, Social Traps, and Geopolitical Conflicts," in Handbook on Ethics in Marketing, A. Nill, ed. Northampton, MA: Edward Elgar, 188-219.

Shultz, Clifford J.II and Anthony Pecotich (1997), "Marketing and development in the transition economies of Southeast Asia: Policy explication, assessment, and implications,” Journal of Public Policy \& Marketing, 16 (1), 55-68.

Silk, John (2000), “Caring at a distance:(im) partiality, moral motivation and the ethics of representation-introduction,” Ethics, Place and Environment, 3 (3), 303-09.

Singer, Peter (1972), “Famine, affluence, and morality,” Philosophy and Public Affairs, 1 (3), 229-43.

Sliwinski, Sharon (2009), "The aesthetics of human rights,” Culture, Theory and Critique, 50 (1), 23-39.

Small, Deborah and George Loewenstein (2003), "Helping a victim or helping the victim: Altruism and identifiability,” Journal of Risk and Uncertainty, 26 (1), 5-16.

Small, Deborah and Nicole Verrochi (2009), “The face of need: Facial emotion expression on charity advertisements,” Journal of Marketing Research, 46 (6), 777-87.

Small, Deborah and Uri Simonsohn (2008), "Friends of victims: Personal experience and prosocial behavior,” Journal of Consumer Research, 35 (3), 532-42.

Smith, David (1998), "How far should we care? On the spatial scope of beneficence," Progress in Human Geography, 22 (1), 15-38. 
Smith, Joanne R., and Andreè McSweeney (2007), “Charitable giving: The effectiveness of a revised theory of planned behaviour model in predicting donating intentions and behaviour,” Journal of Community \& Applied Social Psychology, 17 (5), 363-86.

Sood, By Rahul, Geoffrey Stockdale and Everett Rogers (1987), “How the news media operate in natural disasters,” Journal of Communication, 37 (3), 27-41.

Sousa, Carlos and Frank Bradley (2006), “Cultural distance and psychic distance: Two peas in a pod?,” Journal of International Marketing, 14 (1), 49-70.

Spolaore, Enrico and Romain Wacziarg (2015), “Ancestry, language and culture,” Working Paper, No. 5388, National Bureau of Economic Research.

Sredl, Katherine C., Clifford J. Shultz II, and Ružica Brečić (2017), “The Arizona Market: a Marketing Systems Perspective on Pre-and Post-War Developments in Bosnia, with Implications for Sustainable Peace and Prosperity.” Journal of Macromarketing, 37 (3), 300-16.

Tajfel, Henri and John Turner (1986), “The Social Identity Theory of Intergroup Behaviour,” in Psychology of Intergroup Relations, Worchel, S. and W. G. Austin, eds., Chicago: Nelson-Hall.

Tajfel, Henri (1974), “Social identity and intergroup behaviour,” Social Science Information, $13(2), 65-93$.

Tanguy, Joelle. (2003), “The sinews of humanitarian assistance: Funding policies, practices, and pitfalls,” in Basics of International Humanitarian Missions, Kevin Cahill, ed. New York, NY, Fordham University Pres, 200-40.

The Commonwealth (2018), Member Countries, (accessed on July 18, 2018), [available at http://thecommonwealth.org/member-countries]. 
Thomas, Anita and Laura Kopczak (2005), “From logistics to supply chain management. The path forward in the humanitarian sector,” Fritz Institute, (accessed July 25, 2017), [available at: www.fritzinstitute.org/PDFs/WhitePaper/FromLogisticsto.pdf].

Thomas, David and Elizabeth Ravlin (1995), “Responses of employees to cultural adaptation by a foreign manager,” Journal of Applied Psychology, 80 (1), 133-46.

Ülkü, M. Ali, Kathryn M. Bell, and Stephanie Gray Wilson (2015), “Modeling the impact of donor behavior on humanitarian aid operations,” Annals of Operations Research, 230 (1), 153-68.

UNESCO (2018), Literacy, (accessed on July 18, 2018), [available at http://uis.unesco.org/en/topic/literacy].

United Nations, (2015). Official Development Assistance, (accessed on August 13, 2017), [available at http://iif.un.org/].

Viswanathan, Madhu, José Antonio Rosa, and Julie A. Ruth (2010), “Exchanges in marketing systems: the case of subsistence consumer-merchants in Chennai, India,” Journal of Marketing, 74 (3), 1-17.

Viswanathan, Madhu, Raj Echambadi, Srinivas Venugopal and Srinivas Sridharan (2014), “Subsistence Entrepreneurship, Value Creation, and Community Exchange Systems: A Social Capital Explanation,” Journal of Macromarketing, 34 (2), 213-26.

von Engelhardt, Johannes and Jeroen Jansz (2015), “Distant suffering and the mediation of humanitarian disaster,” in World Suffering and Quality of Life, Ronald Anderson ed., Social Indicators Research Series, Springer, Dordrecht, 56, 75-87.

Wark, Colin and John F. Galliher (2007), “Emory Bogardus and the origins of the social distance scale,” The American Sociologist, 38 (4), 383-95. 
Webb, Deborah, Corliss Green and Thomas Brashear (2000), “Development and validation of scales to measure attitudes influencing monetary donations to charitable organizations,” Journal of the Academy of Marketing Science, 28 (2), 299-309.

Wenar, Leif (2003), “What we owe to distant others,” Politics, Philosophy and Economics, 2 (3), 283-304.

World Bank (2018), GDP per capita (Current US\$), (accessed on July 18, 2018), [available at https://data.worldbank.org/indicator/NY.GDP.PCAP.CD].

Zagefka, Hanna, Masi Noor,Rupert Brown, Georgina de Moura and Tim Hopthrow (2011), "Donating to disaster victims: Responses to natural and humanly caused events," European Journal of Social Psychology, 41 (3), 353-63.

Zaheer, Srilata, Margaret Schomaker and Lilach Nachum (2012), "Distance without direction: Restoring credibility to a much-loved construct,” Journal of International Business Studies, 43 (1), 18-27. 